\title{
Retraction Note to: Wear Mechanism for In Situ TiC Particle Reinforced AZ91 Magnesium Matrix Composites
}

\author{
Junping Yao ${ }^{1}$ Wen $\mathrm{Li}^{1} \cdot$ Lei Zhang ${ }^{1} \cdot$ Fajun Wang $^{1} \cdot$ Mingshan Xue $^{1}$. \\ Hongliu Jiang ${ }^{1} \cdot$ Jinshan $\mathrm{Lu}^{1}$
}

Published online: 22 March 2015

(C) Springer Science+Business Media New York 2015

\section{Retraction Note to: Tribol Lett (2010) 38:253-257 DOI 10.1007/s11249-010-9600-x}

The Editors-in-Chief and the authors have decided to retract the following article "Wear Mechanism for In Situ TiC Particle Reinforced AZ91 Magnesium Matrix Composites" by Junping Yao, Wen Li, Lei Zhang, Fajun Wang, Mingshan Xue, Hongliu Jiang, Jinshan Lu, which appeared in Tribology Letters, Volume 38, Issue 3, pages 253-257, 10.1007/s11249-010-9600-x. Upon investigation, it has been found that the authors have duplicated figures from the following articles:

1. "Effect of in situ TiC particulate on the wear resistance of spray-deposited 7075 Al matrix composite" by
Feng Wang, Huimin Liu, Bin Yang. Materials Characterization, Volume 54, Issues 4-5, May 2005, Pages 446-450.

2. "Tensile and wear behaviour of in situ $\mathrm{Al}-7 \mathrm{Si} / \mathrm{TiB} 2$ particulate composites" by S. Kumar, M. Chakraborty, V. Subramanya Sarma, B.S. Murty. Wear, Volume 265, Issues 1-2, 25 June 2008, Pages 134-142.

Specifically, the authors duplicated Figure 2 from Figure 2 in "Effect of in situ TiC particulate on the wear resistance of spray-deposited 7075 Al matrix composite" and Figures 4 and 5 from Figures 7 and 8 in "Tensile and wear behaviour of in situ $\mathrm{Al}-7 \mathrm{Si} / \mathrm{TiB} 2$ particulate composites", which had the effect of misrepresenting their own experimental results.

The online version of the original article can be found under doi:10.1007/s11249-010-9600-x.

Wen Li

wenl@ualberta.ca

1 School of Materials Science and Engineering, Nanchang Hangkong University, Nanchang 330063,

People's Republic of China 